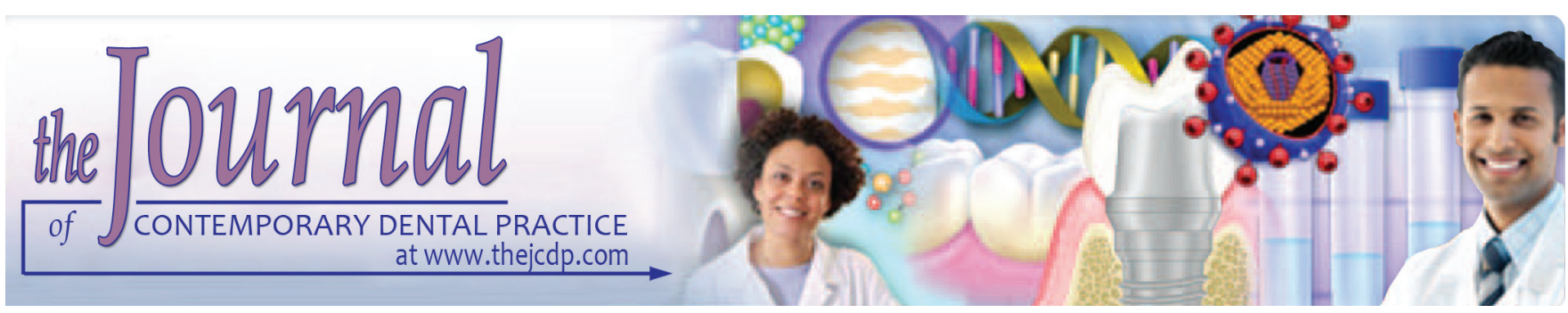

\title{
Proliferative Index in Invasive Tumor Front of Oral Squamous Cell Carcinoma: A Potential Prognostic Indicator
}

\author{
${ }^{1}$ Lipsa Bhuyan, ${ }^{2}$ Sambit Sarangi, ${ }^{3}$ Bijoy K Das, ${ }^{4}$ Surya N Das, ${ }^{5}$ Sarat Nayak
}

\begin{abstract}
Aim: The aim of the study was to evaluate the proliferative index $(\mathrm{PI})$ at their invasive front of oral cancer and their association with Bryne's grades of oral squamous cell carcinoma (OSCC) and compare the PI with lymph node metastasis, site of involvement, and habits.
\end{abstract}

Materials and methods: The $\mathrm{Ki}-67$ antigen expression was immunohistochemically evaluated in a total of 102 cases that included the histopathologically diagnosed archival specimens of OSCCs. They were subdivided by Bryne's histopathological grading into grade I (40 cases), grade II (32 cases), and grade III (30 cases). The nucleus with brown stain was considered positive. Cells were counted under 400x magnification. The proliferative activity thus determined was then expressed as a percentage of $\mathrm{Ki}-67$ labeling index (Ki-67 LI) positive cells.

Results: A stepwise increase in the mean $\mathrm{Ki}-67 \mathrm{LI}$ was found from grade I to III squamous cell carcinoma, thus correlating with the histological grading. In addition, there was a higher PI seen in cases associated with metastatic lymph node, which concords with the higher biologic aggressiveness and poor prognosis of the lesion.

Conclusion: The present study shows a definitive correlation of Ki-67 antigen with the Bryne's histological grading, all the parameters of Bryne's grading for OSCC and lymph node status of the patient proving its association as an effective tool to grade the tumors and finally read the prognosis of the tumor.

${ }^{1}$ Department of Oral and Maxillofacial Pathology, Kalinga Institute of Dental Sciences, KIIT University, Bhubaneswar Odisha, India

${ }^{2-4}$ Department of Oral and Maxillofacial Pathology, S.C.B. Dental College \& Hospital, Cuttack, Odisha, India

${ }^{5}$ Department of Oral and Maxillofacial Pathology, Hi-tech Dental College \& Hospital, Bhubaneswar, Odisha, India

Corresponding Author: Lipsa Bhuyan, Department of Oral and Maxillofacial Pathology, Kalinga Institute of Dental Sciences KIIT University, Bhubaneswar, Odisha, India, e-mail: bhuyanlipsa @gmail.com
Clinical significance: Cell proliferation is regarded as one of the most important biologic mechanisms in oncogenesis. The role of cell proliferation in tumor progression has been inferred in studies concerned with human cancer by comparing the PI of normal tissue, preneoplastic and neoplastic lesions. The Ki-67 antigen-labeled cells can prove to be an effective aid to grade the tumors. It might be possible to standardize and objectify tumor grading among pathology laboratories.

Keywords: Bryne's grading, Immunohistochemistry, Invasive front, Ki-67 antigen, Oral squamous cell carcinoma, Proliferative index.

How to cite this article: Bhuyan L, Sarangi S, Das BK, Das SN, Nayak S. Proliferative Index in Invasive Tumor Front of Oral Squamous Cell Carcinoma: A Potential Prognostic Indicator. J Contemp Dent Pract 2018;19(2):170-176.

\section{Source of support: Nil}

Conflict of interest: None

\section{INTRODUCTION}

Uncontrolled and abnormal proliferation is the basic principle and the mainstay of cancer, which is further complicated by its unpredictable carriage with multistage processes that collectively confound the diagnosis. ${ }^{1}$ In addition to this, the studying of the histopathological profiles of the cancer cell has largely remained subjective, embodying a possibility of individual bias toward mendacious interpretation of the disease. Therefore, a genuine reason thus culminated to find out an objective guideline that would attribute collectively and resultantly for an absolutely clear diagnosis. ${ }^{2}$

The evaluation of the morphologic profile of the tumor cells is considered to be a determinant factor appropriating the aggressiveness of the tumor. However, at times, the inconspicuous nature of such a profile is found to be inadequate to assign the aggressiveness of the lesion. In addition to this, morphologic profiles of the neoplastic cells 
are different and are unisomorphic at different zones in the same field as well as in different fields of the same tumor, thus creating a scope for confusion. It is believed that the most useful prognostic information can be obtained from the invasive front of a tumor, where the deepest and presumably the most aggressive cells reside. In their various recent seminal studies, Bryne ${ }^{3}$ suggested that the invasive front of the tumor is the region which enunciates the cell character and thus, could contribute toward prognosis. ${ }^{4}$

The knowledge of cell proliferative activity and its cellular proteins, which are involved in the control of cell proliferation, are essential components for understanding the biology of tumors. Cell kinetic data may also be a useful adjunct to histologically based tumor classifications, and are among the most important indicators of treatment response and relapse in many types of cancers. ${ }^{5,6}$ In justification of the reasons above, many biologic markers have been proposed to provide information on the differentiation, proliferation, and prognosis of various lesions. Monoclonal antibodies directed toward nuclear antigens are increasingly used as tools to obtain valuable information concerning the proliferative changes of the tumors. The Ki-67 antigen is one such reliable biomarker of cancers, which is now being widely studied to reveal the prognostic indication of the disease. ${ }^{7}$

The Ki-67, a large nonhistone protein with molecular weight of approximately $395 \mathrm{kDa}$, has been extensively used as a marker to read the proliferative activity during the G1, S, G2, and M phases of the cell cycle. In view of its high sensitivity and specificity in neoplastic tissues, Ki-67 has been widely used as a reliable marker in various studies on oral neoplasms. ${ }^{8-11}$

With this view in mind, the present study is designed to elucidate the biological behavior of the cancer cells in OSCC respective to their location, using Ki-67 immunological probe for cellular proliferation. Further, such probes can also reveal the cellular kinetics at the deepest and most invading front of the tumor, which is considered to be a significant histological site disclosing tumor aggression. Hence, Ki-67 antigen-labeled cells can prove to be an effective tool to grade the tumors and finally contribute to the prognosis of the disease.

\section{MATERIALS AND METHODS}

The study material consisted of formalin-fixed, paraffinembedded tissues of histologically diagnosed cases of OSCC retrieved from the Department of Oral and Maxillofacial Pathology, S.C.B Dental College \& Hospital, Cuttack, Odisha, India. The demographic data, details of habit history, their duration of usage, and lymph node involvement of the cases were retrieved from the previous records. The study was approved by the Institutional
Review Board of S.C.B Dental College \& Hospital, Cuttack, Odisha, India.

The tissue blocks were histologically graded based on the Bryne's grading system. Slides where invasive tumor front (ITF) could not be identified were excluded. Totally, 33 cases were diagnosed as grade I OSCC, 27 cases as grade II OSCC, and 30 cases as grade III OSCC. They were evaluated immunohistochemically for Ki-67 with positive and negative controls. Immunohistochemical staining protocol was performed using an advanced polymer staining system. The sections were stained with an antibody directed against the Ki-67 antigen. The antibodies and reagents used for immunohistochemical analysis were obtained from Leica Biosystems, Benton lane, Newcastle, UK. Positive immunoreactivity indicated the presence of brown precipitate in the nucleus at the site of the target antigen. Positive controls of Ki-67 included histopathologically confirmed cases of ameloblastoma. For negative control, tris buffer saline was substituted for primary antibody. These fields were evaluated under 400× magnification (Olympus, BX 51).

\section{Counting of Cells}

All counts were performed with a binocular light microscope (LYNX vision 2000; Lawrence and Mayo) under high power magnification $(400 \times)$. The microscope is fitted with an eyepiece (10x ocular) hauling a grid containing 100 blocks $(10 \times 10)$ so that counting of cells can be proficient and without bias. In each high power field, the cells in the blocks of the grid were counted as represented. The cells counted in each were noted, summed, and submitted for statistical analysis. Cells that lacked a clear nucleus were excluded. In each case, a minimum of 1,000 tumor cells were counted to determine the proliferative activity.

\section{Statistical Analysis}

Once the number of Ki-67 antigen-positive cells per the total number of tumor cells was obtained, to achieve uniformity of the total number of cells counted, the counts were statistically attuned to 1,000 cells in each case. The values were then expressed as a percentage of Ki-67 antigen-positive cells or Ki-67 LI.

The analysis of variance (ANOVA) test was used to compare between different groups of carcinomas. Independent sample t-test and post hoc test were used to assess the significance of pairwise differences between the various study groups. A p-value $<0.05$ was taken to be statistically significant.

\section{RESULTS}

The distribution of Ki-67 antigen-positive cells in the tumor nests of well-differentiated squamous cell carcinoma tissues was usually restricted to the outermost layer 


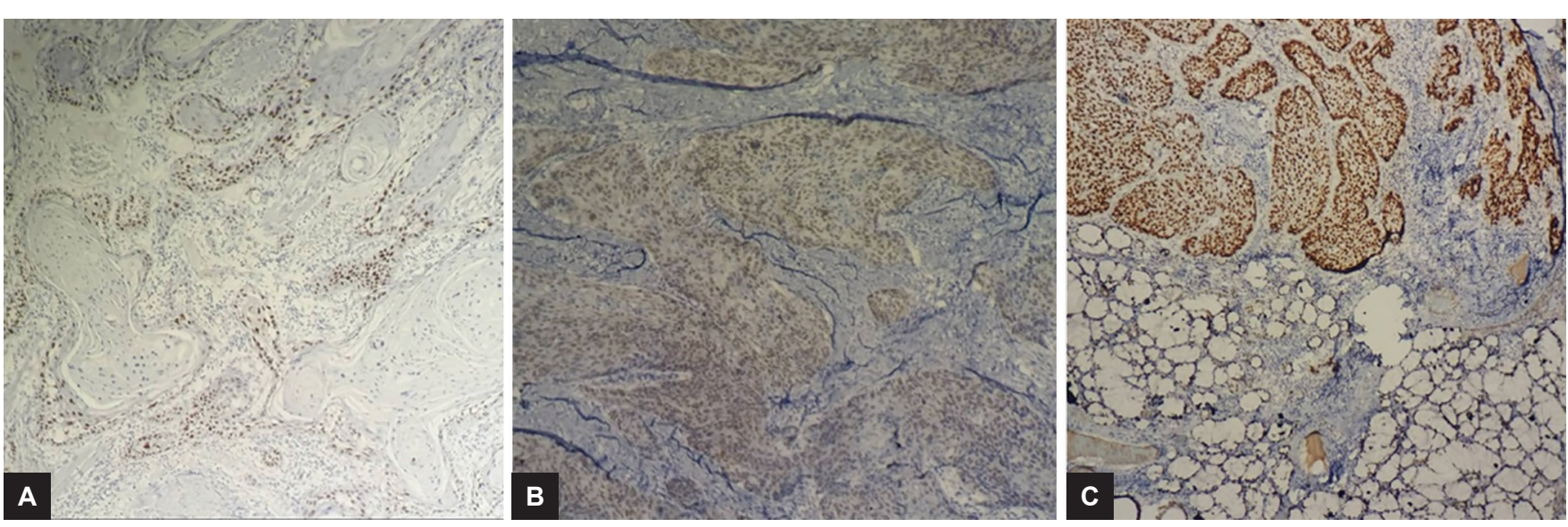

Figs 1 A to C: Ki-67 immunoreactivity in: (A) Well-differentiated; (B) moderately differentiated; and (C) poorly differentiated OSCC 40x

of the tumor cells. In cases of moderately differentiated carcinomas, the expression of Ki-67 antigen in the tumor nests was found to be more diffuse in the inner layers also. In poorly differentiated squamous cell carcinoma, the expression was seen in most of the tumor cells (Fig. 1).

The mean Ki-67 LI in all the three grades of carcinoma were age- and sex-matched. The Ki-67 LI was compared with the grades of OSCC. After evaluating statistically by ANOVA, at $95 \%$ confidence interval, this marker was found to be 76 to $81 \%, 60.67$ to $64.98 \%$, and 32.72 to $36.91 \%$ in grade III, grade II, and grade I, respectively $(\mathrm{p}=0.000)$ (Table 1). A significant difference was seen in mean Ki-67 LI when compared with the histological grades of carcinoma. The ANOVA was followed by post hoc test (least significant difference) showing that the difference was statistically significant in all the pairs $(p=0.00)($ Table 2$)$. A higher mean Ki-67 LI (77.89\%) was found in 38 subjects with lymph node involvement than in 64 subjects with negative lymph node involvement $(48.72 \%)$. Independent sample t-test revealed this difference to be significant $(p=0.000)$. Moreover, on comparing mean Ki-67 LI in the two groups of lymph node status for each grade of carcinoma, it was found that subjects with positive lymph node metastasis had comparatively higher mean Ki-67 LI than subjects with negative lymph node metastasis (Table 3). Comparison of Ki-67 LI and other descriptive statistics along with ANOVA indicated a straight line direct relationship between the Bryne's score and mean $\mathrm{Ki}-67 \mathrm{LI}$. The ANOVA inferred that the mean Ki-67 LI is significantly increased with increase in Bryne's score with $\mathrm{p}=0.000$ (Graph 1).

The study subjects were distributed over eight sites, namely, the palate, buccal mucosa, mucosal surface of lip, gingiva, retromolar area, alveobuccal complex, floor of the mouth, and tongue. Analyzing the data by ANOVA test, the lowest mean level of Ki-67 was found in palate $(45.96 \%)$, and the highest was found in the floor of the mouth $(83.32 \%)$ (Table 4$)$.

The effects of habit and duration of the habit on Ki-67 LI separately and the combined effect of habit and its duration on mean Ki-67 LI were studied through two-way ANOVA. It revealed that in each habit group, the mean

Table 1: Comparison of mean Ki-67 LI by grades of carcinoma

\begin{tabular}{lllllllll}
\hline & & & & & \multicolumn{2}{c}{$95 \%$ confidence interval for mean } & \\
Grades of carcinoma & $n$ & Mean & SD & SE & Lower bound & Upper bound & Minimum & Maximum \\
\hline Grade I OSCC & 40 & 34.815 & 6.544 & 1.035 & 32.722 & 36.908 & 24.400 & 47.800 \\
Grade II OSCC & 32 & 62.825 & 5.963 & 1.054 & 60.675 & 64.975 & 52.400 & 73.200 \\
Grade III OSCC & 30 & 79.130 & 6.691 & 1.222 & 76.632 & 81.628 & 68.000 & 88.000 \\
\hline Total & 102 & 56.636 & 19.782 & 1.959 & 52.751 & 60.522 & 24.400 & 88.000 \\
\hline
\end{tabular}

ANOVA: $d f=2, f=431.058, p=0.000 ;$ SD: Standard deviation; SE: Standard error

Table 2: Comparison of mean Ki-67 LI by pairwise grades of carcinoma

\begin{tabular}{|c|c|c|c|c|c|c|}
\hline \multicolumn{2}{|c|}{ Dependent variable: Ki-67 LI (percentage) } & \multirow{2}{*}{$\begin{array}{l}\text { Mean difference } \\
(I-J)\end{array}$} & \multirow[b]{2}{*}{$S E$} & \multirow[b]{2}{*}{$p$-value } & \multicolumn{2}{|c|}{$95 \%$ confidence interval } \\
\hline (I) Group & (J) Group & & & & Lower bound & Upper bound \\
\hline Grade II OSCC & Grade I OSCC & 28.010 & 1.521 & 0 & 24.992 & 31.028 \\
\hline Grade III OSCC & Grade II OSCC & 16.305 & 1.630 & 0 & 13.071 & 19.539 \\
\hline Grade III OSCC & Grade I OSCC & 44.315 & 1.549 & 0 & 41.242 & 47.388 \\
\hline
\end{tabular}

SE: Standard error 
Proliferative Index in Invasive Tumor Front of Oral Squamous Cell Carcinoma

Table 3: Lymph node status and grades of carcinoma: Cross classification

\begin{tabular}{|c|c|c|c|c|c|c|c|c|}
\hline \multirow[b]{2}{*}{ Grades of carcinoma } & \multicolumn{5}{|c|}{ Ki-67 LI (percentage) } & \multirow[b]{2}{*}{$t$-value } & \multirow[b]{2}{*}{$d f$} & \multirow[b]{2}{*}{$p$-value } \\
\hline & Lymph node status & $n$ & Mean & $S D$ & SE mean & & & \\
\hline \multirow[t]{2}{*}{ Grade I OSCC } & Yes & 7 & 46.400 & 0.957 & 0.362 & 9.023 & 38 & 0 \\
\hline & No & 33 & 32.358 & 4.055 & 0.706 & & & \\
\hline \multirow[t]{2}{*}{ Grade II OSCC } & Yes & 11 & 69.900 & 2.233 & 0.673 & 9.776 & 30 & 0 \\
\hline & No & 21 & 59.119 & 3.267 & 0.713 & & & \\
\hline \multirow[t]{2}{*}{ Grade III OSCC } & Yes & 20 & 83.245 & 3.328 & 0.744 & 10.039 & 28 & 0 \\
\hline & No & 10 & 70.900 & 2.826 & 0.894 & & & \\
\hline
\end{tabular}

SD: Standard deviation; SE: Standard error

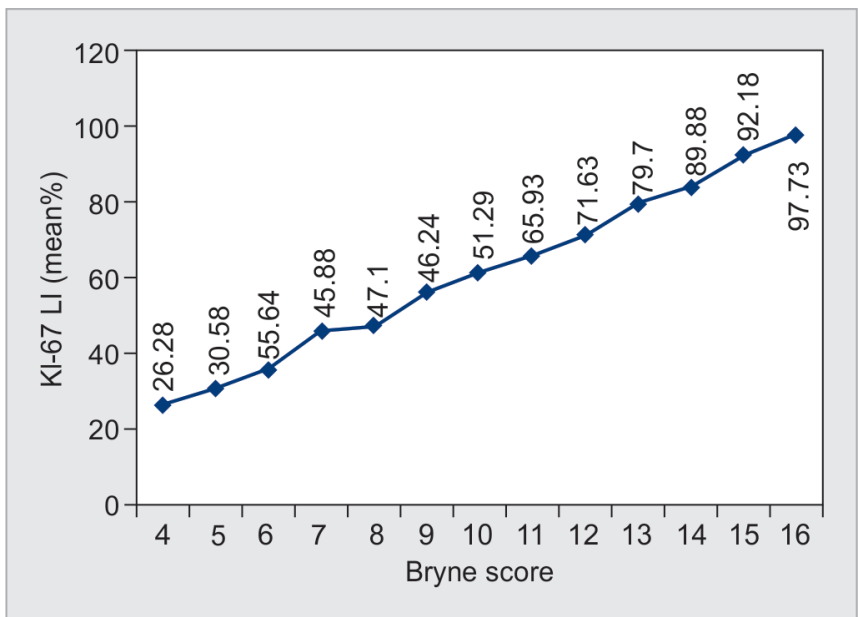

Graph 1: Comparison of Ki-67 LI by Bryne's score level of Ki-67 LI increases with duration. Variation due to habit is not statistically significant, but contribution of the duration of habit to the variation is statistically significant, and the combined effect of habit and its duration to the variation is also not significant. The occurrence of the disease was more in subjects with all the three habits together. However, this was found to be statistically nonsignificant. It was observed that shorter the duration of the habit, lesser was the Ki-67 LI. The combined effects of habit and its duration for all possible combinations were not statistically significant. Post hoc test revealed that there is no significant difference between the pairs of habit group. However, the differences between duration $\leq 25$ years and $>30$ years and between 26 and 30 years and $>30$ years were significant (Tables 5 and 6).

Table 4: Comparison of Ki-67 LI by site of invasion

\begin{tabular}{|c|c|c|c|c|c|c|c|c|}
\hline \multicolumn{5}{|c|}{ Ki-67 LI (percentage) } & \multicolumn{2}{|c|}{ 95\% Confidence Interval for mean } & \multirow[b]{2}{*}{ Minimum } & \multirow[b]{2}{*}{ Maximum } \\
\hline Site of invasion & $n$ & Mean & $S D$ & SE & Lower bound & Upper bound & & \\
\hline Floor of the mouth & 6 & 83.32 & 5.42 & 2.21 & 77.63 & 89.01 & 73.2 & 87.6 \\
\hline Tongue & 6 & 77.23 & 9.66 & 3.94 & 67.10 & 87.37 & 63.4 & 88 \\
\hline Alveobuccal complex & 16 & 61.48 & 20.28 & 5.07 & 50.67 & 72.28 & 29.8 & 87.6 \\
\hline Alveolus & 18 & 55.53 & 20.02 & 4.72 & 45.58 & 65.49 & 25.6 & 83.4 \\
\hline Retromolar area & 8 & 52.49 & 13.47 & 4.76 & 41.23 & 63.75 & 31.1 & 68.8 \\
\hline Buccal mucosa & 26 & 52.42 & 18.55 & 3.64 & 44.93 & 59.91 & 26.3 & 82.5 \\
\hline Labial mucosa & 15 & 48.39 & 19.14 & 4.94 & 37.80 & 58.99 & 24.4 & 81.1 \\
\hline Palate & 7 & 45.96 & 14.67 & 5.54 & 32.39 & 59.52 & 33.2 & 62.8 \\
\hline Total & 102 & 56.64 & 19.78 & 1.96 & 52.75 & 60.52 & 24.4 & 88 \\
\hline
\end{tabular}

ANOVA: Analysis of variance; $\mathrm{df}=7, \mathrm{f}=4.326, \mathrm{p}=0.000$; SD: Standard deviation, SE: Standard error

Table 5: Comparison of Ki-67 LI (\%) habit by duration

\begin{tabular}{lllllll}
\hline & & & & \multicolumn{2}{c}{ 95\% Confidence interval for mean } \\
\cline { 5 - 7 } Habit & Duration (years) & $n$ & Mean & SE & Lower bound & Upper bound \\
\hline C & $\leq 25$ & 11 & 57.591 & 5.803 & 44.662 & 70.520 \\
& $26-30$ & 11 & 45.300 & 5.407 & 33.253 & 57.347 \\
C + S & $>30$ & 15 & 64.853 & 4.935 & 54.268 & 75.438 \\
& $\leq 25$ & 12 & 49.050 & 4.396 & 39.374 & 58.726 \\
& $26-30$ & 8 & 58.550 & 6.733 & 42.629 & 74.471 \\
C + S + A & $>30$ & 13 & 57.562 & 6.302 & 43.830 & 71.293 \\
& $\leq 25$ & 9 & 43.900 & 4.462 & 33.611 & 54.189 \\
& $26-30$ & 6 & 52.333 & 9.776 & 27.204 & 77.463 \\
& $>30$ & 17 & 68.112 & 4.255 & 59.091 & 77.132 \\
\hline
\end{tabular}

SE: Standard error; C: Chewing tobacco; S: Smoking tobacco; A: Alcohol 
Table 6: Association between habit and duration with $\mathrm{PI}$

\begin{tabular}{|c|c|c|c|c|c|c|}
\hline \multicolumn{7}{|c|}{ Analysis of two-way variance parameter estimates (dependent variable-Ki-67 LI, factors habit and duration) } \\
\hline \multicolumn{7}{|c|}{ Dependent variable: Ki-67 LI (percentage) } \\
\hline \multirow[b]{2}{*}{ Parameter } & \multirow[b]{2}{*}{$B$} & \multirow[b]{2}{*}{$S E$} & \multirow[b]{2}{*}{$t$-value } & \multirow[b]{2}{*}{$p$-value } & \multicolumn{2}{|c|}{ 95\% Confidence interval } \\
\hline & & & & & Lower bound & Upper bound \\
\hline Intercept & 68.112 & 4.537 & 15.012 & 0 & 59.102 & 77.122 \\
\hline$[$ Habit $=\mathrm{C}]$ & -3.258 & 6.627 & -0.492 & 0.624 & -16.418 & 9.901 \\
\hline$[$ Habit $=\mathrm{C}+\mathrm{S}]$ & -10.550 & 6.892 & -1.531 & 0.129 & -24.237 & 3.137 \\
\hline$[$ Habit $=C+S+A]$ & 0 & - & - & - & - & - \\
\hline [Duration $=\leq 25$ ] & -24.212 & 7.712 & -3.140 & 0.002 & -39.525 & -8.898 \\
\hline [Duration = 26-30] & -15.778 & 8.883 & -1.776 & 0.079 & -33.419 & 1.862 \\
\hline [Duration $=>30]$ & 0 & - & - & - & - & - \\
\hline$[$ Habit $=\mathrm{C}]{ }^{*}[$ Duration $=\leq 25]$ & 16.949 & 10.706 & 1.583 & 0.117 & -4.310 & 38.209 \\
\hline$[$ Habit $=\mathrm{C}]{ }^{*}[$ Duration $=26-30]$ & -3.775 & 11.578 & -0.326 & 0.745 & -26.767 & 19.217 \\
\hline$[$ Habit $=\mathrm{C}] *[$ Duration $=>30]$ & 0 & - & - & - & - & - \\
\hline$[$ Habit $=\mathrm{C}+\mathrm{S}]{ }^{*}[$ Duration $=\leq 25]$ & 15.700 & 10.749 & 1.461 & 0.148 & -5.646 & 37.046 \\
\hline$[$ Habit $=\mathrm{C}+\mathrm{S}]{ }^{*}[$ Duration $=26-30]$ & 16.767 & 12.230 & 1.371 & 0.174 & -7.519 & 41.053 \\
\hline$[$ Habit $=\mathrm{C}+\mathrm{S}]{ }^{*}[$ Duration $=>30]$ & 0 & - & - & - & - & - \\
\hline$[$ Habit $=\mathrm{C}+\mathrm{S}+\mathrm{A}]{ }^{*}[$ Duration $=\leq 25]$ & 0 & - & - & - & - & - \\
\hline$[$ Habit $=\mathrm{C}+\mathrm{S}+\mathrm{A}] *[$ Duration $=26-30]$ & 0 & - & - & - & - & - \\
\hline$[\text { Habit }=\mathrm{C}+\mathrm{S}+\mathrm{A}]^{*}[$ Duration $=>30]$ & 0 & - & - & - & - & - \\
\hline
\end{tabular}

A: Alcohol-this parameter is set to zero because it is redundant; C: Chewing tobacco; S: Smoking tobacco

\section{DISCUSSION}

Although many techniques such as $3 \mathrm{H}$-thymidine, $\mathrm{BrdU}$ expression, and flow cytometry deoxyribonucleic acid quantification permit the assessment of proliferation, these techniques pose the limitations of procedural feasibilities. The need for absolutely fresh tissue and/or the radioactivity involved makes them unattractive for routine purposes. ${ }^{11,12}$ Assessment of cell kinetic information by immunohistochemical methods using antibodies against proliferating cell nuclear antigen (PCNA) and KI-67 antigen has the recompense of not only conserving cellular and tissue architecture, but also being applicable to routine archival formalin-fixed, paraffin-embedded specimens. ${ }^{13,14}$ The PCNA is not expressed in advanced phases of the cell cycle and cannot be detected by means of immunohistochemical techniques. On the contrary, $\mathrm{Ki}-67$ is present during all active phases of the cell cycle (G1, S, G2, and mitosis), but is absent from resting cells $\left(G_{0}\right)$, which makes it a specific marker for cell proliferation. ${ }^{15}$ Therefore, this marker was aptly selected in this study.

In our study, quantization of positive cells was performed at the tumor invasive front, rather than selected random fields throughout the tumor section. This approach was decided on for two reasons: First, quantitative evaluation of Ki-67 staining in this study showed an increased number of positively stained cells at the tumor front than in the central areas of tumors. A similar finding was observed in many literatures. ${ }^{3,16,17}$ Piffkó et al $^{16}$ stated that the tumor invasive margin might have putative biological significance in epithelial malignancies due to the accumulation of proliferating cells. They further stated that, based on the results of their study and other studies, the invasive tumor margin of squamous cell carcinomas may be the best field for growth fraction estimations in oral cancer. Second, less differentiated cells are present at ITF than the other areas of the tumor and may provide information, i.e., more prognostic. ${ }^{18}$

There were more males than females in all the three groups. It was observed that prevalence of all the grades of OSCC among males are twice than in females, whereas in grade III, it is three times higher. It was found that the mean value of Ki-67 LI in grade I (47.8\%) was double than that of grade III $(88.0 \%)$ and grade II $(73.2 \%)$ having an intermediate value between the two, thus marking a clear-cut difference in the mean value in different grades $(p=0.000$; Table 1). These results are consistent with Tumuluri et $\mathrm{al}_{,}{ }^{19}$ Kurokawa et $\mathrm{al}_{,}{ }^{20}$ Tumuluri et $\mathrm{al},{ }^{21}$ and Premlatha and Uma. ${ }^{22}$ Thus, the assessment of cell proliferation in various types of tumors may prove to be an important adjunct to histologically based tumor classification.

There was a distinct difference in mean Ki-67 LI between grade I and II; grade II and III; and grade III and I. This difference was statistically significant in all the pairs (Table 2). This marked variation in the amount of Ki-67 within different tumor grades has proven to show the bonafidity of the PI and, hence, considered to be a beneficial tool to evaluate prognosis. Premlatha and $\mathrm{Uma}^{22}$ found a statistically significant difference between Ki-67 LI of well- and poorly differentiated OSCC. The Ki-67 LI of moderately differentiated OSCC did not have 
statistically significant differences with either well- or poorly differentiated OSCC. This observation reflected the subjective nature of the Broder's grading system.

In the presence of oral cancer, the metastatic lymph node may be considered as a locoregional spread of the primary lesion and, therefore, directly corresponds to the aggressiveness of the lesion. In addition, lymph nodes in this study are confirmed to be positive for metastatic postsurgical histopathologic evaluation. Comparison of Ki-67 LI was done between the subjects with presence or absence of lymph node metastasis. It was found that 38 subjects with lymph node involvement have a significantly higher mean Ki-67 LI (77.89\%) than 64 subjects with negative lymph node involvement (48.72\%). Moreover, on comparing mean Ki-67 LI in the two groups of lymph node status for each grade of carcinoma, it was found that subjects with positive lymph node metastasis had comparatively higher mean Ki-67 LI than subjects with negative lymph node metastasis (Table 3 ). These observations were in consonance with the study by Motta et $\mathrm{al}^{23}$ Thus, it may be implicated that tumors with a high cell PI (such as the mean Ki-67 LI) may indicate a potential for these tumors to metastasize.

Bryne's score denotes the cumulative score of degree of keratinization, nuclear pleomorphism, lymphoplasmacytic infiltration, and pattern of invasion. Bryne's scores range from 4 to 16 , a score of 4 indicating lowest and 16 indicating the highest level of aggression of the tumor. A direct relationship was observed between the Bryne's score and mean Ki-67 LI (Graph 1). From this result, it may be inferred that the mean Ki-67 LI correlates with the biologic aggressiveness of the tumor.

The lower mean Ki-67 LI in the palate may be explained by the fact that such anatomical sites may initially offer rigid bony resistance for local invasion. In addition, this is also a site for easy and early visualization of the lesion warranting early attention for medical care, and therefore, it does not leave any scope for the lesion to progress. On the contrary, the mean Ki-67 LI in the floor of the mouth is the highest among all anatomical sites, which may be explained by the fact that the same is considered to be a favorable site for rapid proliferation and deeper invasion of the malignant cells due to the cumulative effects of abundant vascularity, absence of any biological barrier, and a typical site in which the positive gravitational force favors vertical seeding of cells. Further, this is an anatomic site where direct inspection of lesion does not take place unless it is symptomatic and leaving a scope for sampling when it is hopelessly advanced (Table 4). There was increase in mean Ki-67 LI between tongue and floor of mouth, which was in consonance with the study conducted by Watanabe et $\mathrm{al}^{24}$ Therefore, the more aggressive behavior of carcinoma in the floor of the mouth appears to be correlated with a higher proliferation activity, as indicated by the Ki-67 expression.

Association between habit and contribution of the duration of habit to the variation was not statistically significant (Tables 5 and 6). The fact is that other genetic and epigenetic factors, including habits such as chewing and smoking tobacco and alcohol, may serve as a potential etiology that may affect oral carcinogenesis.

\section{CONCLUSION}

Despite many painstaking advances in recent years, cancer still remains as a baffling disease complex confronting the medical sciences until today. Due to uncertainty in its etiology and behavior, the cancer projects a great challenge not only to the public health system, but also underlies a frustrating attempt to control the same. In the array of its complexities, the microscopic interpretation, determination, and the clinical diagnosis still remain a large area of confusion and conflict. However, the basic and the fundamental knowledge about the cancer is that they are uncontrolled abnormal proliferating cells, which depart from the pattern of behavior of normal cells. The present scenario of modern oral oncology is characterized by a better understanding of cellular morphology and the molecular foundation of normal cellular biology. Identification of oral cancer although based on the clinical findings, the heterogeneity of the same still remains an unfolded area for assessing their severity and, hence, stands as hurdle for planning an accurate treatment.

Although there have been many meteoric and erudite advances in the recent years in the field of cancer research disclosing their queer behavior endowed in variable appearances, their biological uncertainties still keep them from clear understanding, thereby posing a great challenge for management.

The present study shows definitive correlation of Ki-67 antigen with the Bryne's histological grading, all the parameters of Bryne's grading for OSCC and lymph node status of the patient proving its association as an effective tool to grade the tumors and finally read the prognosis of the tumor. Although these data suggest that it may be possible to standardize Ki-67 scoring among pathology laboratories, various clinically important discrepancies may persist. Before recommending this biomarker for clinical use, future research is needed to extend this approach to biopsies and whole sections and accounting for staining variability, and link to outcomes.

\section{REFERENCES}

1. Zargaran M, Eshghyar N, Baghaei F, Moghimbeigi A. Assessment of cellular proliferation in oral verrucous carcinoma and well-differentiated oral squamous cell carcinoma 
using Ki67: A non-reliable factor for differential diagnosis? Asian Pac J Cancer Prev 2012;13(11):5811-585.

2. Kurokawa H, MatsumotoS, Murata T, Yamashita $Y$, Tomoyose T, Zhang M, Fukuyama H, Takahashi T. Immunohistochemical study of syndecan-1 down-regulation and the expression of p53 protein or ki-67 antigen in oral leukoplakia with or without epithelial dysplasia. J Oral Pathol Med 2003 Oct;32(9):513-521.

3. Bryne $M$. Is the invasive front of an oral carcinoma the most important area for prognostication? Oral Dis 1998 Jun;4(2):70-77.

4. Nadaf A, Bavle RM, Soumya M, D'mello S, Kuriakose MA, Govindan S. Analysis of the invasive edge in primary and secondary oral squamous cell carcinoma: An independent prognostic marker: A retrospective study. J Oral Maxillofac Pathol 2016;20(2):239-245.

5. Tsuji T, Sasaki K, Kimura Y, Yamada K, Mori M, Shinozaki F. Measurement of proliferating cell nuclear antigen (PCNA) and its clinical application in oral cancers. Int J Oral Maxillofac Surg 1992 Dec;21(6):369-372.

6. van Dierendonck JH, Wijsman JH, Keijzer R, van de Velde CJ, Cornelisse CJ. Cell-cycle-related staining patterns of antiproliferating cell nuclear antigen monoclonal antibodies. Comparison with brdUrd labeling and ki-67 staining. Am J Pathol 1991 May;138(5):1165-1172.

7. Whitfield ML, George LK, Grant GD, Perou CM. Common markers of proliferation. Nat Rev Cancer 2006 Feb;6(2):99-106.

8. Bôas DS, Takiya CM, Coelho-Sampaio TL, Monção-Ribeiro LC, Ramos EA, Cabral MG, dos Santos JN. Immunohistochemical detection of ki-67 is not associated with tumor-infiltrating macrophages and cyclooxygenase- 2 in oral squamous cell carcinoma. J Oral Pathol Med 2010 Aug;39(7):565-570.

9. Chen WJ, He DS, Tang RX, Ren FH, Chen G. Ki-67 is a valuable prognostic factor in gliomas: Evidence from a systematic review and meta-analysis. Asian Pac J Cancer Prev 2015;16(2):411-420.

10. Katori H, Nozawa A, Tsukuda M. Increased expression of cyclooxygenase-2 and ki-67 are associated with malignant transformation of pleomorphic adenoma. Auris Nasus Larynx 2007 Mar;34(1):79-84.

11. van Diest PJ, van der Wall E, Baak JP. Prognostic value of proliferation in invasive breast cancer: A review. J Clin Pathol 2004 Jul;57(7):675-681.

12. Quinn CM, Wright NA. The clinical assessment of proliferation and growth in human tumours: Evaluation of methods and applications as prognostic variables. J Pathol 1990 Feb;160(2):93-102.
13. Bologna-Molina R, Mosqueda-Taylor A, Molina-Frechero N, Mori-Estevez AD, Sánchez-Acuña G. Comparison of the value of PCNA and ki-67 as markers of cell proliferation in ameloblastic tumors. Med Oral Patol Oral Cir Bucal 2013 Mar;18(2):e174-e179.

14. Noel JC, Heenen M, Peny MO, Fayt I, Peny J, De Dobbeleer G, Haot J, Galand P. Proliferating cell nuclear antigen distribution in verrucous carcinoma of the skin. Br J Dermatol 1995 Dec;133(6):868-873.

15. Scholzen T, Gerdes J. The ki-67 protein: From the known and the unknown. J Cell Physiol 2000 Mar;182(3):311-322.

16. Piffkó J, Bánkfalvi A, Ofner D, Kusch F, Böcker W, Joos U, Schmid KW. In situ assessment of cell proliferation at the invasive front of oral squamous cell carcinomas. Virchows Arch 1996 Nov;429(4-5):229-234

17. Dissanayake U, Johnson NW, Warnakulasuriya KA. Comparison of cell proliferation in the centre and advancing fronts of oral squamous cell carcinomas using ki-67 index. Cell Prolif 2003 Oct;36(5):255-264.

18. Bryne M. Prognostic value of various molecular and cellular features in oral squamous cell carcinomas: A review. J Oral Pathol Med 1991 Oct;20(9):413-420.

19. Tumuluri V, Thomas GA, Fraser IS. Analysis of the Ki-67 antigen at the invasive tumor front of human oral squamous cell carcinoma. J Oral Pathol Med 2002 Nov;31(10):598-604.

20. Kurokawa H, Zhang M, Matsumoto S, Yamashita Y, Tanaka T, Tomoyose T, Takano H, Funaki K, Fukuyama H, Takahashi T, et al. The relationship of the histologic grade at the deep invasive front and the expression of ki-67 antigen and p53 protein in oral squamous cell carcinoma. J Oral Pathol Med 2005 Nov;34(10):602-607.

21. Tumuluri V, Thomas GA, Fraser IS. The relationship of proliferating cell density at the invasive tumour front with prognostic and risk factors in human oral squamous cell carcinoma. J Oral Pathol Med 2004 Apr;33(4):204-208.

22. Premlatha BR, Uma K. Analysis of KI-67 antigen in human oral squamous cell carcinoma-an immunohistochemical study. J Int Oral Health 2010 Jun;2(1):9-16.

23. Motta Rda R, Zettler CG, Cambruzzi E, Jotz GP, Berni RB. Ki-67 and p53 correlation prognostic value in squamous cell carcinomas of the oral cavity and tongue. Braz J Otorhinolaryngol 2009 Jul-Aug;75(4):544-549.

24. Watanabe S, Watanabe R, Oton-Leite AF, Alencar RC, Oliveira JC, Leles CR, Batista AC, Mendonça EF. Analysis of cell proliferation and pattern of invasion inoral squamous cell carcinoma. J Oral Sci 2010 Sep;52(3):417-424. 